\title{
Alignment Methods in Rotating Equipment
}

\author{
Isitro Trejo Moreno \\ Tlaxcala University of Technology \\ City, Country Puebla, México \\ Oscar Hernández Hernández \\ Tlaxcala University of Technology \\ City, Country Tlaxcala, México \\ José Luis Hernández Corona \\ Tlaxcala University of Technology \\ City, Country Tlaxcala, México
}

\begin{abstract}
This research provides an analysis about the need to implement innovative alignment techniques and to diversify the methods to carry it out, if there is outdated equipment, misalignment becomes more recurrent and this causes the equipment to present failures as high vibration, high temperature, product leaks, excessive energy consumption and wear of some equipment components.
\end{abstract}

In turn, this text exposes the methodologies of alignment of axes by straight edge, dial indicator, and by laser alignment, and makes a comparison of the advantages and disadvantages between these three methods to conclude which of them brings greater benefits to the industry today.

Keywords:- Alignment, Straight Edge, Dial Indicator, Laser Alignment, Misalignment.

\section{INTRODUCTION}

This research addresses the issue of axis alignment, which can be defined as the process by which the rotating axes are made to coincide with the fixed axes so that they are on the same line. Likewise, this document deals with three different alignment methodologies, straight edge method, dial indicator tool, and laser alignment are addressed.

The main characteristic of the alignment is the difficulty in handling the measurement instruments, therefore, carrying it out becomes complex and requires a high level of knowledge.

This research is presented due to the lack of implementation of cutting-edge equipment for alignment, as well as the lack of knowledge about the advantages that laser alignment provides, resulting in considering it as a piece of expensive equipment, and not worthy and not profitable to buy it. This is of great interest once the characteristics of each method and their degree of profitability have been analyzed. Therefore, this article allows us to contrast information about which is the best method for shaft alignment.

\author{
Yair de Jesús González Pérez \\ Tlaxcala University of Technology \\ City, Country Puebla, México \\ Aline Díaz Ramírez \\ Tlaxcala University of Technology \\ City, Country Tlaxcala, México \\ Ernesto Mendoza Vazquez \\ Tlaxcala University of Technology \\ City, Country Tlaxcala, México
}

\begin{abstract}
$>$ Alignment and misalignment
Machinery alignment refers to the fact that: "the rotation axes of the machines must be collinear (one axis of rotation is the projection of the other), and the above is considered under normal operating or working conditions (that is, temperature, load, and speed)" (1). By what is understood to the alignment of shafts as the process that is carried out to achieve the exact union of the line of the axis centers and the proper positioning of the rotating machines that are mounted in series or in parallel position to avoid wear on flexible elements, in addition to eliminating vibration and high temperatures that occur in machinery in an irregular alignment.
\end{abstract}

Correct alignment results in good performance, better operation and greater availability of the machinery, less wear on the flexible coupling elements, forced labor on the pumps and motors is reduced, the maintenance of the machinery goes from being corrective to preventive, cost reduction in repairs and spare parts and risky conditions are avoided.

In turn, misalignment is defined as "the deviation of the (physical) axis in relation to the position of a collinear axis of rotation measured at the power transmission points when the equipment is running under normal operating conditions" (2). It should be noted that misalignment can be angular and parallel, viewed horizontally or vertically.

Misalignment has negative consequences for mutually aligned pumps and motors, among the affected components bearings, seals, shafts, couplings, and set screws can be mentioned.

\section{$>$ Alignment methodologies and materials}

There are different alignment methods and materials; in this article the alignments by straight edge, dial indicator, and laser alignment are described.

\section{Straight edge alignment}

This alignment method is the simplest and its results are considered as approximate or prior to a more precise alignment since its readings are direct. This method is the most limited of the three because it is only used with small couplings of equal size and its shape is quite variable. In order to do this, a straight edge is needed that includes a 
graduated scale divided into units of length such as millimeters or inches and shims, which are sheets of different thicknesses to measure the clearance between the shafts.

The method by straight edge is detailed below:

- Determine which will be the fixed machine and which will be the mobile one.

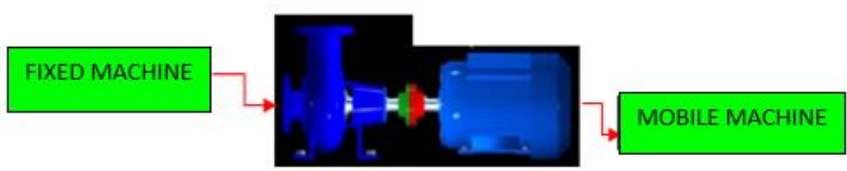

Fig 1:- Fixed machine and mobile machine

- Establish the convention signs that will be worked on during this method.

- Uncouple mobile and fixed equipment.

- Record the readings obtained when starting the alignment to show current conditions.

- Divide the couplings of the fixed and mobile machine clockwise.

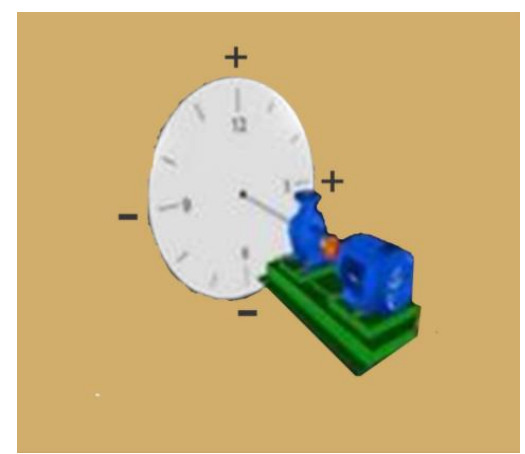

Fig 2:- Four positions: 12 o'clock, 3 o'clock, 6 o'clock and 9 o'clock.

- The straight edge is placed on the couplings (mobile and fixed), joining them to measure the parallel and horizontal angular misalignment at the 12 o'clock and 6 o'clock positions, clockwise.

- The correction is made by moving the mobile machine horizontally, in such a way that the parallel horizontal misalignment between them decreases and at the same time, tilting the equipment to correct the horizontal angular misalignment until the measurement is as less erroneous as possible.

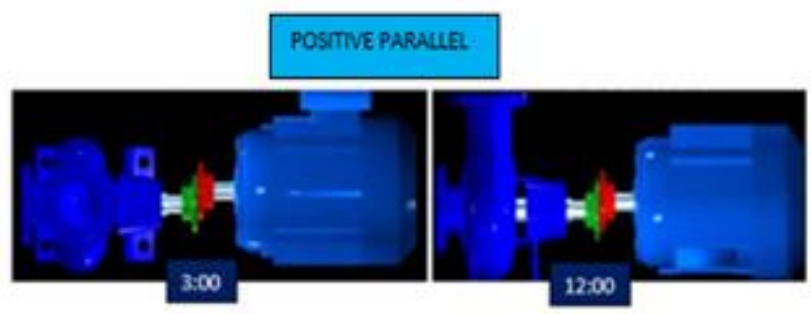

Fig 3:- Positive parallel

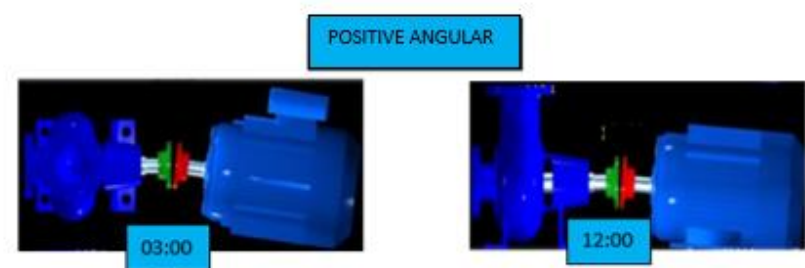

Fig 4:- Positive angular

- Once the horizontal misalignment has been corrected, the straight edge is placed on the couplings of both machines, to measure the parallel and angular vertical misalignment. In the same way, the mobile equipment is moved but now vertically, and if necessary, also inclined to also correct the vertical angular misalignment and obtain an aligned measurement.

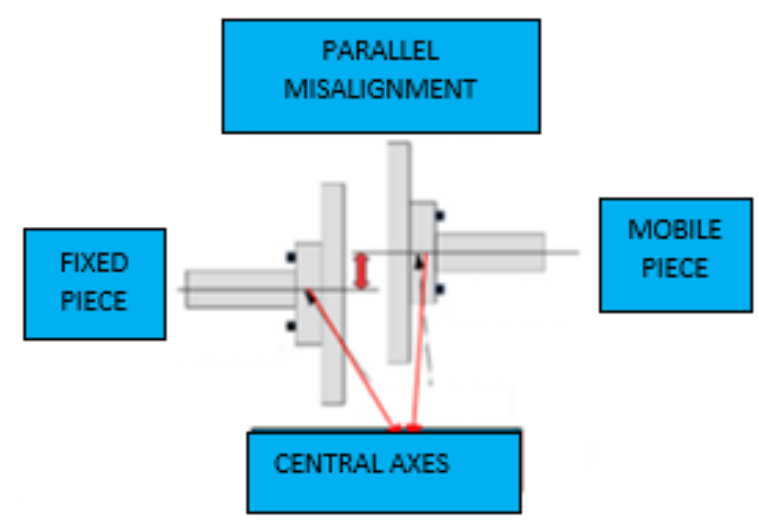

Fig 5:- Parallel misalignment

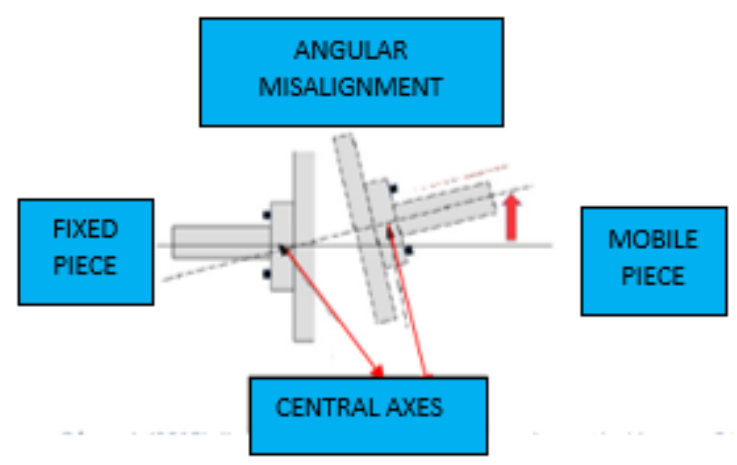

Fig 6:- Angular misalignment

- Final readings are recorded after alignment is performed and compared to those recorded at the start of alignment.

- The fixed machine is coupled with the rotating machine.

\section{Dial Indicator Alignment}

"Dial indicator alignment is performed with a high degree of precision in the quantitative evaluation of shaft positions under static conditions. This instrument works through an axis called a spindle that is used to determine the readings that are reflected in the indicator needle" (3). 


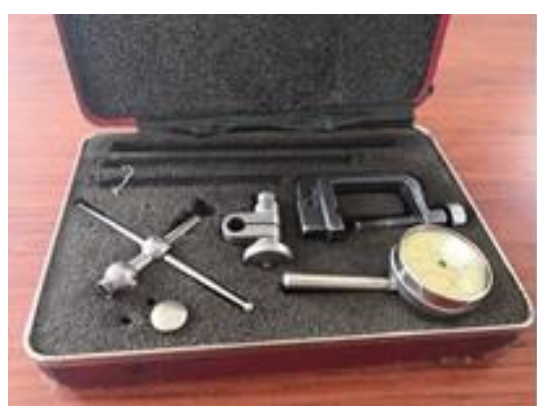

Fig 7:- Dial indicator and its accessories

The steps to carry out a correct alignment by dial are the following:

- Define which of the machines will be fixed and which will be mobile.

- Set the gauges as shown in the figure.

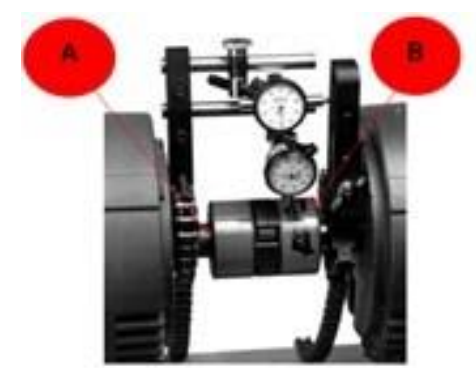

Fig 8:- The positioning of indicator clocks

- The bracket is installed on-axis "A". Subsequently, by means of the indicator, the sweep is carried out in the circumference of the "B" axis coupling.

- The clock probe should exert pressure against the circumference of the coupling ensuring that the probe stroke is lowered by half.

- The indicator hands should be turned until zero is reached.

- Once the watch is set, four measurements are taken at the following positions a) .- $\left.\left.0^{\circ}, \mathrm{b}\right) .-90^{\circ}, \mathrm{c}\right) .-180^{\circ}$ and $270^{\circ}$.

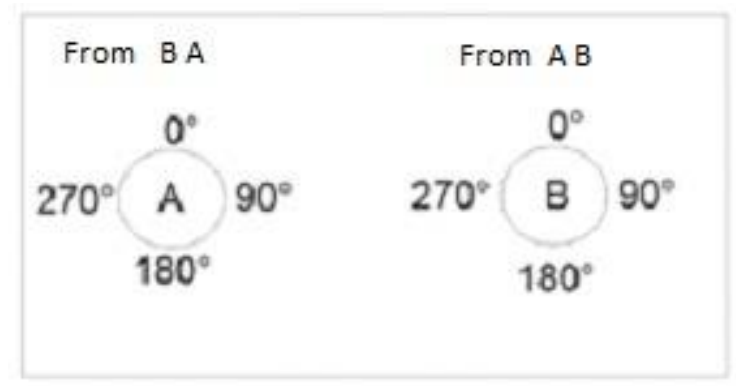

Fig 9:- Measurements position

\section{Laser alignment}

The equipment used to perform a laser alignment is The Combi-Laser Alignment System. This kit consists of a carrying case, an LCD display module, a TD-S transmitter / static sensor, a TD-M transmitter / mobile sensor, two anodized aluminum V-brackets, a plastic rod bracket, two brackets stainless steel, two magnetic bases, a spirit level, a tape measure, two stainless steel chains, $3 \mathrm{~m}$ and $5 \mathrm{~m}$ cables for the display, a $115 \mathrm{VAC}-6 \mathrm{VDC}$ charger and a thermal Epson printer.

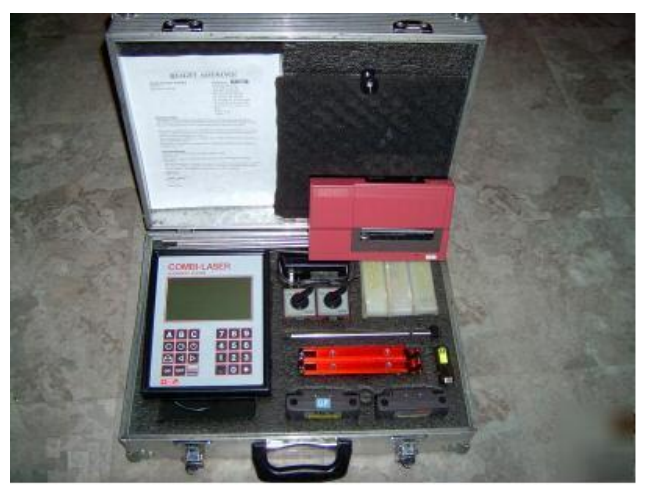

Fig 10:- The Combi-Laser Alignment System

To carry out the laser alignment method, the following instructions are followed:

- Place the magnetic bases and the stainless-steel chains on both axes, since the alignment method of the magnetic bases is by spirit level.

- Once the alignment level is as accurate as possible, secure the bases to the shafts by means of setscrews fixed in the magnetic bases.

- Couple the sensors and the steel bars, the TD-M sensor is coupled to the moving shaft, which goes to the motor and the TD-S sensor is coupled to the static shaft.

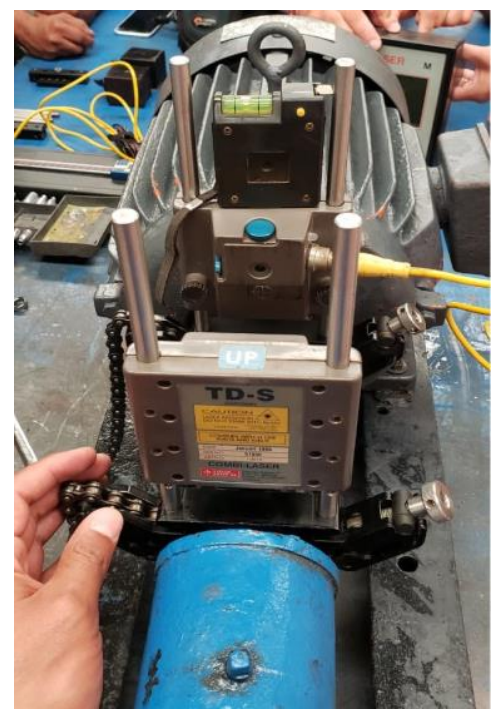

Fig 11:- Coupling of laser sensors

- Immobilize the shafts by means of the stainless-steel chains. If there is movement, the alignment will be canceled.

- Connect the sensors with the cables to the LCD display module.

- As the sensors turn on, a beam of laser light emitted by both sensors is observed.

- When the laser light is reflected on both sensors, adjust the height of the sensors so that it aligns with the marks on each sensor. 
- The LCD module is turned on and it requests the following data using the tape measure:

$\checkmark$ The distance between both sensors.

$\checkmark$ The distance from the center of the coupling to the TDM sensor.

$\checkmark$ The distance between the TD-M sensor and the first engine nut.

$\checkmark$ The distance between the nuts that holds the motor.

- Capture the data through the panel integrated into the LCD module.

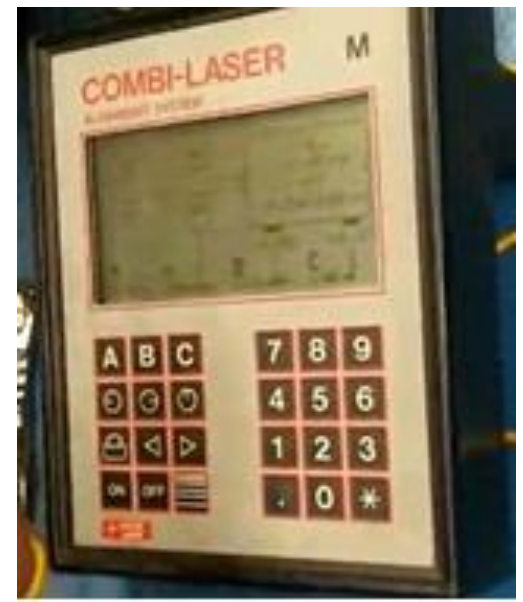

Fig 12:- LCD display module

- Again the LCD module requires the motor revolutions to be captured, these are found on the data plate that is on the upper motor casing.

- The LCD module indicates to rotate the shaft along with the sensors in 3 measurements which are $0^{\circ}, 180^{\circ}$, and $90^{\circ}$.

- Capture every move with the buttons built into the control panel.

- The LCD displays the two types of results, one vertical and the other horizontal. In the vertical result (figure 13) the motor is seen in a lateral position and indicates that alignment shims must be added or removed. When the measurement returns a minus sign, shims are added, when it returns a plus sign, they are removed. The value of the shims is indicated on the LED display. These are added or removed on both nuts, either front or back.

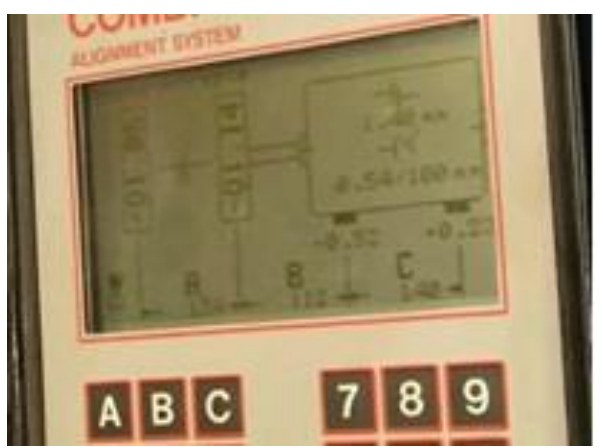

Fig 13:- Result of vertical alignment

- In the horizontal measurement (figure 14) the motor is viewed from the top and indicates how to adjust the motor relative to the plates with set screws.
- Once the variables have been corrected, perform the alignment again from the point where the $0^{\circ} 180^{\circ}$ and $90^{\circ}$ measurements are requested to be captured

You should proceed with the present methodology until the equipment tolerance becomes satisfactory.

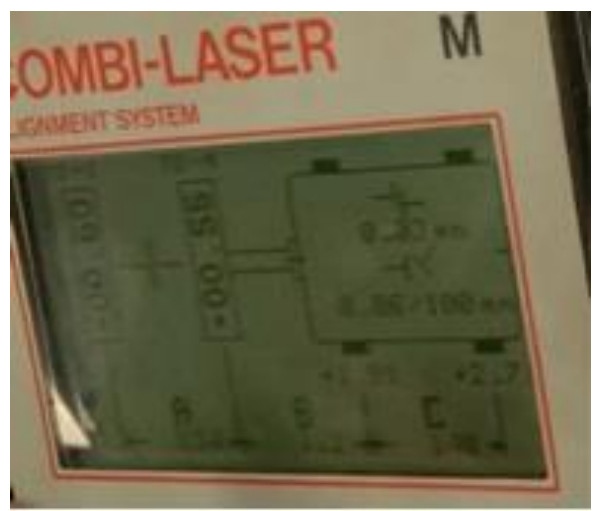

Fig 14:- Result of horizontal alignment

\section{RESULTS AND DISCUSSION}

$>$ Advantages and disadvantages of alignment types

In order to carry out the present analysis, a test bench was designed that allowed the performance of alignment practices by straight edge and by dial indicator, while, for the laser alignment analysis, the corresponding authorization was requested from a maintenance company (name omitted for legal reasons) to witness the operation of the laser equipment.

\section{Straight edge method}

\section{- Advantage}

One of the main advantages of straight edge alignment is that "this alignment tool is still used and commonly has its place in the precision alignment process, in order to obtain an initial alignment" (4). Another privilege that this method presents is its low cost since the investment required for the used material is minimal.

Lastly, it can be stated that even personnel with minimal training can do it since it does not require great precision or greater knowledge.

\section{- Disadvantages}

The main disadvantage of this type of alignment is that it has a very high degree of inaccuracy, which generates high temperatures and vibrations in an initial state, and if it is the only method used, it can fluctuate in shaft twists and even total losses in mobile and fixed equipment.

Due to the evolution in the machinery, the alignment by straight edge is inefficient due to the high speeds that this reach; for this reason, this type of alignment is only used in old machines that do not generate high revolutions. 


\section{$>$ Dial indicator}

- Advantage

One of the most outstanding advantages of dial indicator is that "they are used for measurements such as flatness, circularity, cylindricity, sphericity, concentricity, deviation, displacement, and so on" (5).

Teams operating at high speeds benefit from this type of alignment because the indicators can measure misalignment from different rotational angles, bringing them closer to a higher degree of accuracy.

At the time of installation of the dial indicator, it is easy to install them in different ways and, when carrying out the alignment, the operators can have greater access to the machinery and perform their tasks more easily.

In dial alignment, measurements taken every $90^{\circ}$ can be made coincidentally both parallel and angular.

\section{- Disadvantages}

It is a method that does not have the cutting-edge characteristics that are required for the machinery that companies have today.

Dial measurements are given in varying ranges and for the accuracy required in dial alignment, this method requires a greater investment of time.

Operators who perform the dial alignment process must be experts; as otherwise, misalignment generates great losses of time due to the lengthy process involved. In turn, the operators of the machinery at the time of taking the readings make errors due to various factors.

Like the alignment by straight edge, it is an oldfashioned method and, if it presents some degree of imprecision, it can cause great losses of time and machinery.

Errors will always occur due to the rounding of each reading when calculating the results.

The readings offered by the dial indicator are not always real, as due to vibration the needles settle at wrong values, due to that "Small gaps may not be noticed, but they produce considerable errors in the results" (6).

\section{Laser alignment}

\section{- Advantages}

It is the most modern method for shaft alignment when compared to traditional methods (straight edge and dial indicators) it offers better alignment precision since everything is measured by sensors.

Laser alignment requires less investment in terms of execution time and, as technological innovation, has a higher degree of acceptance among operating personnel.
Laser systems are intuitive to use, so they require brief training for their correct operation, and all systems have guides for users.

Laser alignment presents different types of economic advantages, among the main ones, are time, maintenance, and energy consumption, in turn, it increases the life of the equipment.

Machinery failures are reduced due to alignment accuracy, so be it, vibration, equipment, and temperature.

The laser alignment system periodically generates an alignment status assessment.

Taking laser alignment readings is always accurate, so the likelihood of human error is minimal.

Laser systems have the ability to repeat data and store it for protection.

Misalignment in laser systems can be corrected due to the tolerance scale it contains.

The results of the laser alignment method are instantaneous and can be viewed in real-time.

\section{- Disadvantages}

The cost of laser equipment is very high and is usually not in stock of many suppliers, so it is very difficult to acquire.

It is important that at the time of acquiring the laser alignment equipment they have the corresponding certification to be able to work in high temperatures, due to this; the cost of these types of equipment is even higher. Besides, whenever working with laser alignment equipment it is important to verify that it is an area free of explosive gases.

\section{CONCLUSION}

Once the different alignment methodologies have been applied bench and analyzed in the test, as well as the advantages and disadvantages of each of these has been identified, it is concluded that the optimal method to carry out this process is the laser alignment.

Despite having a very high cost, the profitability offered by this equipment is that the entire alignment procedure is optimized, this is reflected in a lower investment of time by operating personnel when carrying out the alignment process, less wear of the machinery, the corrective maintenance provided to the equipment is reduced, human errors are reduced to a minimum, the immediacy of the results is guaranteed and there is cutting edge equipment.

Finally, the tasks can be implemented under this methodology in spite of the disadvantages that it has, with the necessary permissions and required security regulations. 


\section{ACKNOWLEDGMENT}

We are grateful for the support given by the professors of the Tlaxcala University of Technology, who have served as guide throughout this research process.

In the second instance, we appreciate the support of all the members of our family, who are the main sense of obtaining our achievements.

Finally, we appreciate every contribution made to improve and achieve this goal.

\section{REFERENCES}

[1]. Santamaría R. Consideraciones prácticas y económicas del alineamiento de maquinaría. [Internet]. Querétaro: México; 2020 [Accessed 2020 July 24th]. Available at: https://reliabilityweb.com/sp/articles/entry/consideraci ones-practicas-y-economicas-del-alineamiento-demaquinaria

[2]. Torres A. Estudio del desalineamiento entre máquinas acopladas y análisis de su respuesta vibratoria. [Internet]. Concepción: Chile; 2013 [Accessed 2020 Aug 1st]. Available at: http://webcache.googleusercontent.com/search?q=cac he:IU2pEArxsjoJ:repobib.ubiobio.cl/jspui/bitstream/1 23456789/415/1/Torres_Cuevas_Ariel_Alexis.pdf+\& $\mathrm{cd}=2 \& \mathrm{hl}=\mathrm{es} \& \mathrm{ct}=\mathrm{clnk} \& \mathrm{gl}=\mathrm{mx}$

[3]. Piotrowski J. Shaft Alignment Measuring Tools. In: Faulkner L, editor. Shaft Alignment Handbook. $3^{\text {rd }}$ ed. Ohio: CRC Press; 2007. p. 225-226.

[4]. Amu E. Diseño e implementación de un banco didáctico para alineación de elementos rotativos. [Internet]. Santiago de Cali: Colombia; 2007 [Accessed 2020 Aug 2nd]. Available at: https://red.uao.edu.co/bitstream/10614/6253/1/T04261 .pdf

[5]. EcuRed. Indicador de carátula. [Internet]. 2019 [Accessed 2020 Ago 02nd]. Available at: https://www.ecured.cu/Indicador_de_car\%C3\%A1tula

[6]. PRÜFTECHNIK. Porqué alinear las máquinas. [Internet]. Ismaning: Alemania; 2011 [Accessed 2020 Jul 24th]. Available at: http://www.mydmantenimientopredictivo.com/pdf/por -que-alinear.pdf 